\title{
Morphological Changes of Gingiva in Streptozotocin Diabetic Rats
}

\author{
C. Tesseromatis, ${ }^{1}$ A. Kotsiou, ${ }^{2}$ H. Parara, ${ }^{1}$ E. Vairaktaris, ${ }^{3}$ and M. Tsamouri ${ }^{4}$ \\ ${ }^{1}$ Department of Pharmacology, Medical School, University of Athens, Mikras Assias 75, 11527 Goudi, Greece \\ ${ }^{2}$ Pharmacy Department, Aretaeion University Hospital, Vassilis Sophias 76, 11528 Athens, Greece \\ ${ }^{3}$ Department of Craniofacial Surgery, Medical School, University of Athens, Mikras Asias 75, 11527 Goudi, Greece \\ ${ }^{4}$ Department of Pathology, Red Cross Hospital, Red Cross Street, 11526 Athens, Greece \\ Correspondence should be addressed to C. Tesseromatis, ctesser@med.uoa.gr
}

Received 3 July 2008; Accepted 7 November 2008

Recommended by Robin Seymour

Gingivitis and periodontitis are chronic bacterial diseases of the underlying and surrounding tooth tissues. Diabetes mellitus is responsible for tooth deprivation both by decay and periodontal disease. The streptozotocin-induced diabetes results in a diabetic status in experimental animals similar to that observed in diabetes patients. The aim of the study was to investigate the relationship between the gingival lesions and the microangiopathy changes in streptozotocin-induced diabetes mellitus. Forty male Wistar rats were divided into two groups (control and experimental). Diabetes mellitus was induced by $45 \mathrm{mg} / \mathrm{kg}$ IV streptozotocin. The histological investigation of the marginal gingival and the relevant gingival papilla showed inflammation of the lamina propria and the squamous epithelium as well as marked thickness of the arteriole in the diabetic group, but no changes were observed in the control group. The results suggested a probable application of a routine gingival histological investigation in diabetic patients in order to control the progress of disease complications. It may be concluded that histological gingival investigation can be used as a routine assay for the control of the diabetic disease and prevention of its complications.

Copyright ( 2009 C. Tesseromatis et al. This is an open access article distributed under the Creative Commons Attribution License, which permits unrestricted use, distribution, and reproduction in any medium, provided the original work is properly cited.

\section{Introduction}

Gingivitis and periodontitis are chronic bacterial diseases of the underlying and surrounding tooth tissues. The initial factor in the development of the periodontal disease is the host response and its defense capacity to the microbial stimuli. Systemic factors modify all forms of gingivitis and periodontitis through their effect on the physiological immune and inflammatory defense. It has been reported [1] that nerve fibers are involved in the neurogenic inflammation induced by mechanical or chemical irritations in the gingival and the underlying tissues. It has also been suggested that in diabetes mellitus the unmyelinated small diameter fibers are impaired as a result of diabetic neuropathy. Furthermore, many studies have been focused in the impairment of bone mass, occurring in diabetes mellitus. Microangiopathy at the bone tissue was suggested as a possible cause of diabetic osteopenia [2]. Diabetes can have an impact on the bone through multiple pathways, some with contradictory effects, including obesity, changes in insulin levels, higher concentrations of advanced glycation end products in collagen, hypercalciuria associated with glycosuria, reduced renal function, lower insulin-like growth factor-I, microangiopathy, and inflammation [3].

Furthermore, diabetes mellitus is responsible for tooth deprivation both by decay and periodontal disease. Systemic diseases are associated with a higher experience of caries, a high ratio of decayed-to-present teeth, and more gingival and periodontal problems. Patients with high blood pressure, osteoporosis or diabetes mellitus tended to have poorer gingival or periodontal conditions, fewer teeth, and higher risk of edentulousness [4]. In addition, it was found that a larger number of oral streptococci adhered to the tooth surfaces are observed in nonobese diabetogenic mice that spontaneously develop insulin-dependent diabetes mellitus [5].

The aim of the study was to investigate the relationship between the development of gingival lesions and the 


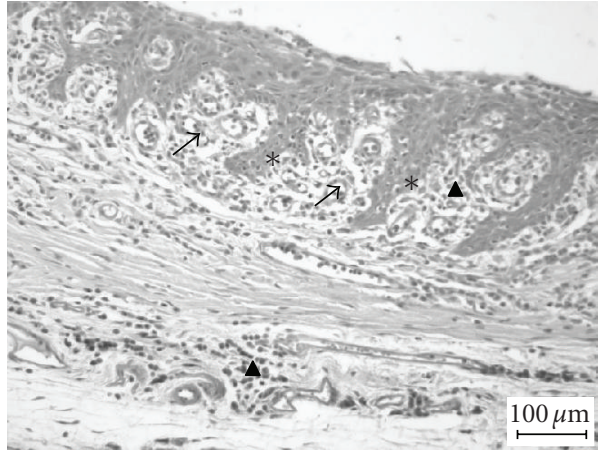

Figure 1: ( $\Delta$ ) Focal perivascular and diffuse inflammation of the lamina propria, $(\uparrow)$ neo-angiogenesis, and $(*)$ hyperplasia of the squamous epithelium.

presence of microangiopathy in streptozotocin-induced diabetes mellitus.

\section{Material and Methods}

Forty male Wistar rats of average body weight of $200 \mathrm{~g}$ were divided into groups A (experimental $n=20$ ) and B (control, $n=10$ ). They were housed five per cage at a constant room temperature $\left(22 \pm 1^{\circ} \mathrm{C}\right)$ under a 12-hour light/12-hour dark (light period 00.8-20.00 hours) cycle. Food and water were provided ad libitum. Animals were cared for accordance with the principles of the "Guide for the Care and Use of Experimental Animals" [6]. The animals of group A were injected once IV with streptozotocin $45 \mathrm{mg} / \mathrm{kg}$ in the jugular interna. The duration of the experiment was 90 days. The blood glucose levels were estimated every week with washoff strips (Dextrostix, Ames Division, Miles Laboratories, Rexdale, Ontario, Canada) in blood obtained from the tail vessels. In parallel, glucose was also qualitatively assayed in urine with urineteststrips (Glukotest Accu-test Roche). The animals' body weight as well as their food intake was determined. The animals were sacrificed by decapitation, and gingiva specimens obtained from the incisor area of the mandible were washed with water and then conserved in $10 \%$ formalin solution for further histological examination with the light microscope. The histological slices of gingival specimens were stained with haematoxylin-eosin by light microscope. The values were expressed as mean \pm standard deviation $(\mathrm{m} \pm \mathrm{SD})$. The statistical analysis was performed by Student's $t$-test and by $x^{2}$ analysis. $P<.05$ was considered as an acceptable level of significance.

\section{Results}

The induction of diabetes mellitus was assessed the day after streptozotocin injection by evaluating clinical symptoms such as frequent urination, increased appetite, and weight loss. In comparison to the control group, the experimental animals exerted a hyperphagia accompanied with an increased daily food consumption. Furthermore, the streptozotocin animals had increased serum glucose and increased

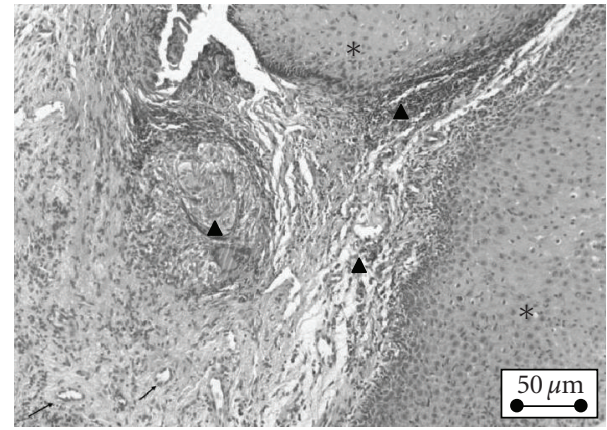

Figure 2: (*) Hyperplasia of the squamous epithelium, ( $\mathbf{\Delta}$ ) diffuse and perivascular inflammation of the lamina propria, and $(\uparrow)$ thickening of the wall of some arterioles.

Table 1: Clinical indices and laboratory findings upon diabetes mellitus induction.

\begin{tabular}{lcc}
\hline & Control animals & $\begin{array}{l}\text { Streptozotocin-injected } \\
\text { animals }\end{array}$ \\
\hline $\begin{array}{l}\text { Daily food intake (g) } \\
\text { Body weight (sacrifice } \\
\text { day) g }\end{array}$ & $14,86 \pm 5,09$ & $19,25 \pm 0,95^{* *}$ \\
Hb Alc (\%) & $5,5 \%$ & $160 \pm 20^{* *}$ \\
Serum glucose mg/dL & 90 & $8,2 \pm 1,4 \% \%^{* *}$ \\
\hline
\end{tabular}

** $P<, 001$ versus control.

TABLE 2: Histological findings.

\begin{tabular}{lcc}
\hline Margin gingival incisor area & Diabetes mellitus & Control \\
\hline Inflammation & +++ & + \\
Neoangiogenesis & +++ & + \\
Vessel wall thickness & +++ & + \\
\hline Buccal/lingal gingiva & & + \\
\hline Hyperkeratosis & +++ & - \\
Epithelium hypertrophy & ++ & -
\end{tabular}

glycosylated haemoglobin (Hb Alc) levels. The severity of diabetes was indicated by the statistically significantly decreased body weight in the experimental animals in comparison to controls $P<, 001$ (Table 1 ). The quantity of daily food intake was increased in diabetic animals compared to controls. Blood glucose levels were significantly increased in the experimental group (Table 1). The levels of $\mathrm{Hb}$ A1c were lower in the control compared to the experimental group. The urination of the experimental group was frequent and the shavings of the cages needed to be changed twice daily.

The experimental animals had a mortality of $10 \%$ during the experimental period, while all the control animals remained alive until the end of the experimental procedure.

The histological findings of the experimental group were as follows. Through haematoxylin-eosin stain, the biopsies from the marginal gingivae and the gingival papillae from the incisor area showed inflammation of the lamina propria, formation of new vessels with various wall thicknesses, and 


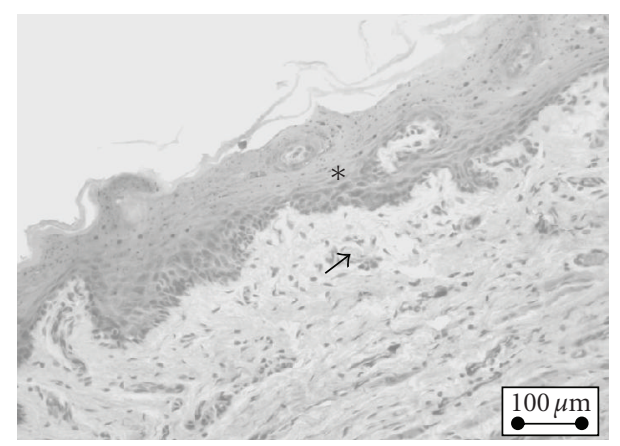

Figure 3: $(*)$ Normal gingival mucosa. normal squamous epithelium, $(\uparrow)$ normal propria vasculature, and absence of inflammation.

hyperaemia. This alteration was localized in the internal site of the gingiva, which was in contact with the tooth surface.

The gingival specimens obtained from the molar area of the mandible of the buccal and lingual sites showed moderate to high hyperceratosis and mild inflammation. All the experimental animals showed moderate-to-severe angiitis, which was not observed in the control animals (see Table 2, Figures 1 and 2).

\section{Discussion}

Recent drastic increase in diabetic population poses serious problems in both health sciences and socioeconomic services. The recent drastic increase in the diabetic population poses serious problems in both health sciences and socioeconomic services. The most important issue in the clinical management of diabetic patients is the chronic complications that contribute to a high morbidity and mortality $[7,8]$.

Hyperglycaemia, as a common feature of diabetes mellitus, is a cause of different pathogenic mechanisms influencing endothelial function.

Diabetes mellitus results in the development of large and micro-vessel damage. A series of changes occur independently of the presence of atherosclerosis. The abnormalities include accumulation of PAS-positive material, laminin, fibronectin, type IV collagen, and connective tissue with lack of acid mucopolysaccharides, and deposition of calcium. It is of particular interest that accumulation of PAS-positive material and lack of acid mucopolysaccharides are recognized as the histological markers of diabetic microangiopathy $[2,8-12]$.

In this study, the administration of streptozotocin in rats induced a diabetic status in the experimental animals similar to that observed in diabetic patients, as shown by the manifested clinical symptoms in accordance with previously reported literature $[2,13,14]$.

The changes observed in bed vasculature concerned macro- and microangiopathy. The extention of microangiopathy is known to impair the function of various organs and systems and common problems are manifested as retinopathy, nephropathy, and neuropathy [15]. Periodontal disease is considered as the sixth complication of diabetes mellitus. It has long been observed that diabetic patients have greater tooth loss due to periodontal disease than nondiabetics of comparable age [16]. The severity of the periodontal disease is absolutely influenced by the degree of diabetic status [17]. The phenomenon may be due to the high tissue glucose concentration, as well as to the presence of metabolic products of the impaired glucose metabolism and it is recognized histologically as enlarged vessel wall with a narrowing of vessel lumen diameter. This process induces disabilities of vessel wall and, in general, leads to abnormal vasculature $[12,18]$. Our results are in agreement with those of other investigators, who reported narrowing of vessel lumen diameter in diabetic subjects as observed by the increased uptake of PAS deposition in the vessel walls [9].

These changes can be aggravated through inflammatory cell infiltration that occurs after one week of steptozotocin treatment in the gingivomucosal tissue as reported by Fehér et al. [1]. Despite multiple and long-term studies, the pathophysiology of diabetic microangiopathy and its pathogenesis are not fully elucidated. Under chronic hyperglycemia, early stimuli elicit adaptive reactions of tissues showing acute inflammatory processes of vessel walls and changes of microangiopathy. The impaired glucose metabolism is recognized histologically as enlarged vessel wall with a narrowing of vessel lumen diameter. This situation in dental care can be recognized by delay healing of tooth extraction sockets, periradical lesions, and periodontal disease $[4,19,20]$.

In addition, it has been suggested that the unmyelinated small-diameter afferent nociceptive C-fibers are impaired in diabetes mellitus, which indicates that in the streptosotocininduced diabetic rat, gingivomucosal tissue is the prerequisite for neurogenic inflammation induced by mechanical or chemical irritations causing a pronounced vessel permeability. Furthermore, diabetic changes may be accompanied by decreased collagen production in rat periodontal tissue [21].

This process induces disabilities of vessel wall such as narrowed vessel calibre and in general leads to the formation of an abnormal vasculature $[12,19]$. Since the ability of the diabetic's circulation to distribute blood is affected, especially during increased blood flow causing severe disturbances, the surrounding and underlying tooth tissues have poor nourishment, which, in relation to the high blood glucose levels, promotes the colonization of overdeveloped microflora in the oral cavity [22]. The presence of PAS material deposition in gingival vessel can be considered as an index of severe diabetic damage [9]. Therefore, slow flow of nutrients and high infection liability promote the destruction process of the periodondium [23].

An important injury that leads to severe handicap in diabetic patients is the development of retinopathy that usually leads to blindness [24]. Most recently, it has been proven that the risk of proliferative diabetic retinopathy was higher in the presence of the periodontal disease [25]. In addition, the occurrence of neuropathy in long-term type 2 diabetes is related to tooth loss and tempomandibular joint disfunction [26].

Therefore, the investigation of the surrounding oral cavity tissues in diabetic patients can demonstrate changes or signs that may alert the physician to control or prevent the 
development of diabetes mellitus. Furthermore, histological gingival analysis may be routinely utilized for the control of the diabetic disease and perhaps may be considered as a diagnostic method of the severity of the disease.

\section{Acknowledgments}

This study was funded by the University of Athens. Many thanks are expressed to Dr. Filia Stratigea (veterinary surgeon) for her significant assistance.

\section{References}

[1] E. Fehér, A. Gyorffi, and Á. Fazekas, "Neurogenic inflammation of gingivomucosal tissue in streptozotocin-diabetic rat," Archives of Physiology and Biochemistry, vol. 109, no. 3, pp. 230-233, 2001.

[2] G. Leidig-Bruckner and R. Ziegler, "Diabetes mellitus a risk for osteoporosis?" Experimental and Clinical Endocrinology \& Diabetes, vol. 109, supplement 2, pp. S493-S514, 2001.

[3] A. V. Schwartz, "Diabetes mellitus: does it affect bone?" Calcified Tissue International, vol. 73, no. 6, pp. 515-519, 2003.

[4] G. Maupomé, C. M. Gullion, B. A. White, C. C. Wyatt, and P. M. Williams, "Oral disorders and chronic systemic diseases in very old adults living in institutions," Special Care in Dentistry, vol. 23, no. 6, pp. 199-208, 2003.

[5] M. Abdus Salam, N. Matsumoto, K. Matin, et al., "Establishment of an animal model using recombinant NOD.B10.D2 mice to study initial adhesion of oral streptococci," Clinical and Diagnostic Laboratory Immunology, vol. 11, no. 2, pp. 379386, 2004.

[6] Committee on Care and Use of Laboratory animals, Guide for the Care and Use of Laboratory Animals, Institute of Laboratory Animal Resources, National Research Council, Washington, DC, USA, 1985.

[7] J. A. Florence and B. F. Yeager, "Treatment of type 2 diabetes mellitus," American Family Physician, vol. 59, no. 10, pp. 2835 2844, 1999.

[8] D. K. Fett, H. Hommel, and U. Fischer, "Die Sauerstoff und Glucoseaufnahme durch die Gingiva bei Diabetes Mellitus mit unterschidliedlichen Parodontopathieformen," Stomatologie der DDR, vol. 25, no. 4, pp. 267-272, 1975.

[9] J. L. Andresen, L. M. Rasmussen, and T. Ledet, "Diabetic macroangiopathy and atherosclerosis," Diabetes, vol. 45, supplement 3, pp. S91-S94, 1996.

[10] T. Ledet, L. Heickendorff, and L. M. Rasmussen, "Pathology of macrovascular disease," Bailliere's Clinical Endocrinology and Metabolism, vol. 2, no. 2, pp. 391-405, 1988.

[11] L. E. De Las Casas and J. L. Finley, "Diabetic microangiopathy in the small bowel," Histopathology, vol. 35, no. 3, pp. 267-270, 1999.

[12] J. J. Keene Jr., "Arteriosclerotic changes within the diabetic oral vasculature," Journal of Dental Research, vol. 54, no. 1, pp. 7782, 1975.

[13] B. Mompeõ, F. Ortega, L. Sarmiento, and I. Castaño, "Ultrastructural analogies between intimal alterations in veins from diabetic patients and animals with STZ-induced diabetes," Annals of Vascular Surgery, vol. 13, no. 3, pp. 294-301, 1999.

[14] B. L. Mealey, "Diabetes and periodontal disease: two sides of a coin," Compendium of Continuing Education in Dentistry, vol. 21, no. 11, pp. 943-946, 2000.

[15] J. A. Davidson, "Treatment of the patient with diabetes: importance of maintaining target $\mathrm{HbA}_{1 \mathrm{c}}$ levels," Current
Medical Research and Opinion, vol. 20, no. 12, pp. 1919-1927, 2004.

[16] R. C. Oliver and T. Tervonen, "Periodontitis and tooth loss: comparing diabetics with the general population," The Journal of the American Dental Association, vol. 124, no. 12, pp. 71-76, 1993.

[17] H. Rose, "The relationship of hyperglycemia to periodontal disease," Journal of Periodontology, vol. 44, no. 5, pp. 303-308, 1973.

[18] B. Emeryk and A. Emeryk, "Reactivity of periodontal vessels in children with insulin-dependent diabetes," Czasopismo Stomatologiczne, vol. 43, no. 8, pp. 453-458, 1990.

[19] H. Devlin, H. Garland, and P. Sloan, "Healing of tooth extraction sockets in experimental diabetes mellitus," Journal of Oral and Maxillofacial Surgery, vol. 54, no. 9, pp. 1087-1091, 1996.

[20] A. Iwama, N. Nishigaki, K. Nakamura, et al., "The effect of high sugar intake on the development of periradicular lesions in rats with type 2 diabetes," Journal of Dental Research, vol. 82, no. 4, pp. 322-325, 2003.

[21] M. Schneir, M. Imberman, N. Ramamurthy, and L. Golub, "Streptozotocin-induced diabetes and the rat periodontium: decreased relative collagen production," Collagen and Related Research, vol. 8, no. 3, pp. 221-232, 1988.

[22] J. Pucher and J. Stewart, "Periodontal disease and diabetes mellitus," Current Diabetes Reports, vol. 4, no. 1, pp. 46-50, 2004.

[23] D. A. Grant-Theule, "Periodontal disease, diabetes, and immune response: a review of current concepts," The Journal of the Western Society of Periodontology/Periodontal Abstracts, vol. 44, no. 3, pp. 69-77, 1996.

[24] H. Henrich, "Relationship between diabetic retinopathy and the condition of the marginal periodontium and residual dentition," Deutsche Zahnärztliche Zeitschrift, vol. 35, no. 3, pp. 421-425, 1980 (German).

[25] H. Noma, I. Sakamoto, H. Mochizuki, et al., "Relationship between periodontal disease and diabetic retinopathy," Diabetes Care, vol. 27, no. 2, p. 615, 2004.

[26] H.-L. Collin, L. Niskanen, M. Uusitupa, et al., "Oral symptoms and signs in elderly patients with type 2 diabetes mellitus: a focus on diabetic neuropathy," Oral Surgery, Oral Medicine, Oral Pathology, Oral Radiology, \& Endodontics, vol. 90, no. 3, pp. 299-305, 2000. 


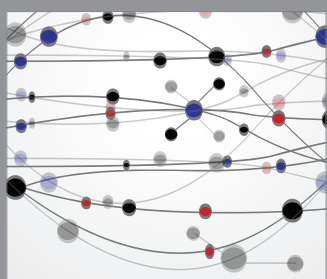

The Scientific World Journal
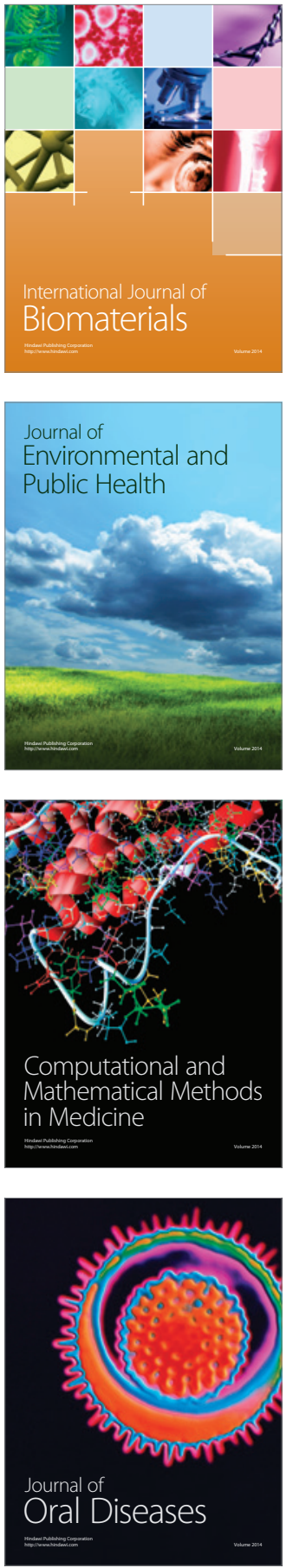
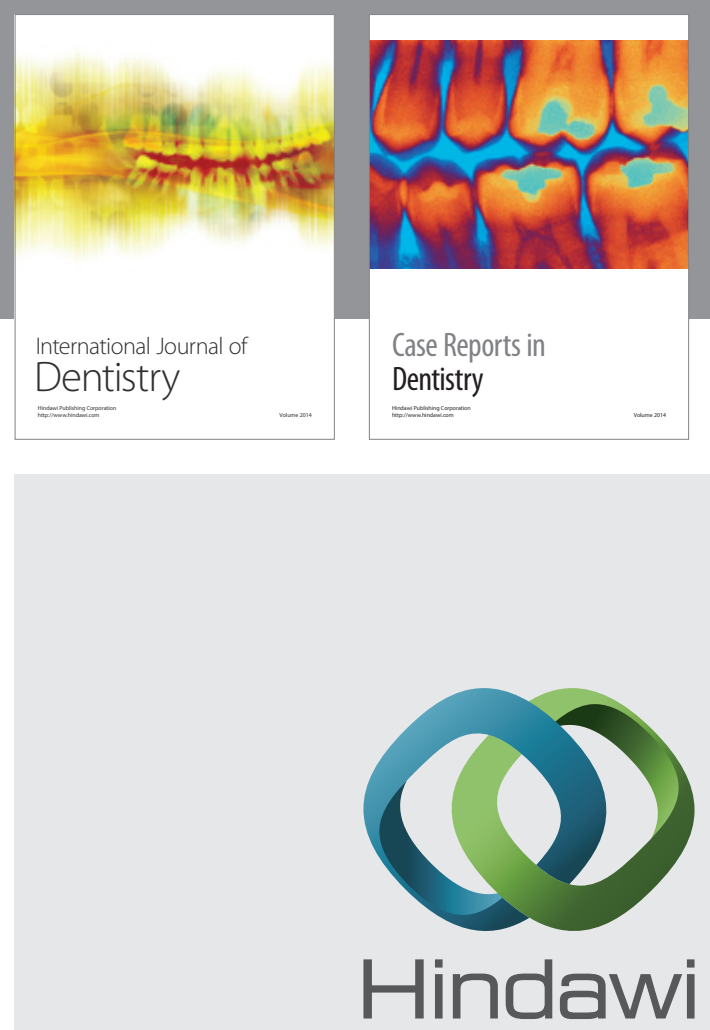

Submit your manuscripts at

http://www.hindawi.com
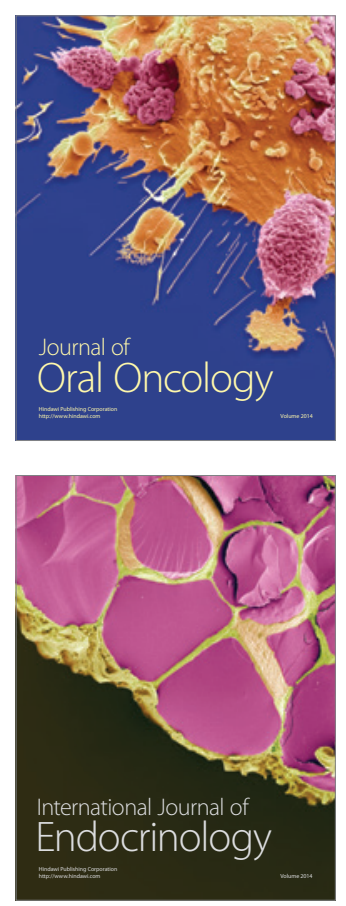
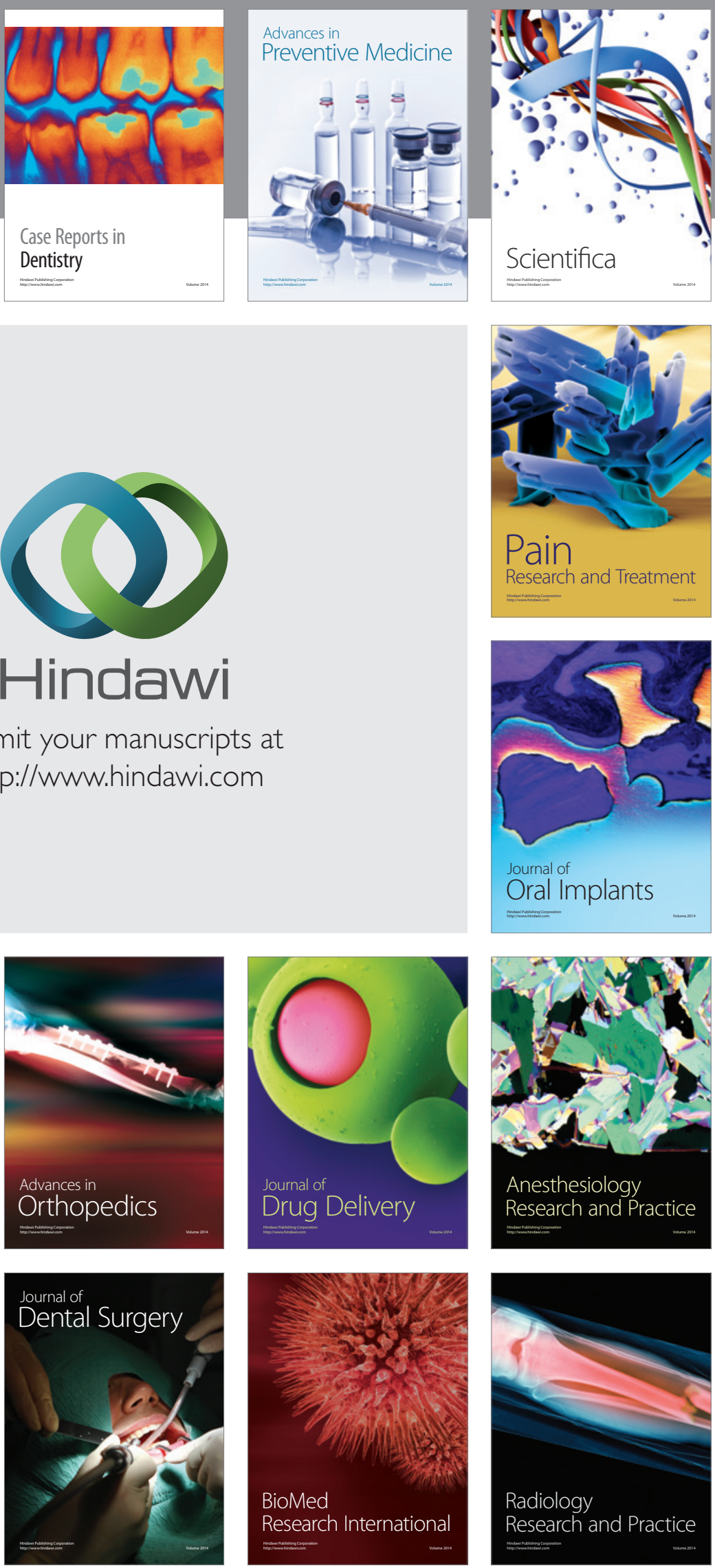